\title{
Alterações físicas, fisiológicas e químicas durante o armazenamento de duas cultivares de sapoti
}

\author{
Patrícia Lígia Dantas de Morais ${ }^{(1)}$, Luiz Carlos de Oliveira Lima(1), Ricardo Elesbão Alves(2), \\ Heloisa Almeida Cunha Filgueiras ${ }^{(2)}$ e Adriano da Silva Almeida ${ }^{(2)}$
}

(1)Universidade Federal de Lavras, Caixa Postal 37, CEP 37200-000 Lavras, MG. E-mail: plmorais@hotmail.com, Icolima@ufla.br (2)Embrapa Agroindústria Tropical, Caixa Postal 3.761, CEP 60511-110 Fortaleza, CE. E-mail: elesbao@cnpat.embrapa.br, heloisa@cnpat.embrapa.br

\begin{abstract}
Resumo - O objetivo deste trabalho foi avaliar alterações físicas, fisiológicas e químicas, durante a maturação de duas cultivares de sapoti (Manilkara sapota L.), relacionando-as às taxas respiratórias e de liberação de etileno. Os frutos foram colhidos no estádio de maturidade fisiológica, avaliados no dia da colheita e armazenados em temperatura de $26 \pm 2^{\circ} \mathrm{C}$ e umidade relativa de $55 \pm 5 \%$. A atividade respiratória e a produção de etileno foram determinadas diariamente; perda de massa, firmeza, acidez total titulável, $\mathrm{pH}$, sólidos solúveis, açúcares solúveis totais e senescência foram avaliados nos tempos de 0, 2, 4, 6, 8, 10 e 12 dias de armazenamento. A cultivar BRS-228 teve pico respiratório, produção de etileno e senescência retardada em relação à cultivar BRS-227. A cultivar BRS-228 manteve maior firmeza, maiores teores de sólidos solúveis e açúcares solúveis totais, e menor perda de massa do que a cultivar BRS-227. A cultivar BRS-228 apresenta maior potencial de conservação póscolheita do que a cultivar BRS-227.
\end{abstract}

Termos para indexação: Manilkara sapota, climatérico, etileno, amadurecimento.

\section{Physical, physiological and chemical changes during storage of two sapodilla cultivars}

\begin{abstract}
The objective of this work was to evaluate the physical, physiological and chemical changes during storage of two sapodilla cultivars (Manilkara sapota L.). Fruits were picked and evaluated at the physiological maturation point, and stored at temperature of $26 \pm 2^{\circ} \mathrm{C}$ and $55 \pm 5 \%$ relative humidity. Respiration activities and ethylene production were daily evaluated, while the loss of mass, firmness, pulp color, total titratable acidity, $\mathrm{pH}$, soluble solids content, total sugar and senescence were determined in the $0,2,4,6,8,10$ and 12 days of storage. Fruits of BRS-228 cultivar had respiration activities, ethylene production picks and senescence retarded when compared to BRS-227 cultivar. Fruits of BRS-228 maintained larger firmness, soluble solids and total sugar contents and smaller loss of mass than BRS-227. The cultivar BRS-228 presents higher postharvest storage potential than BRS-227.
\end{abstract}

Index terms: Manilkara sapota, climateric, ethylene, ripening.

\section{Introdução}

O sapotizeiro (Manilkara sapota L.) é nativo do Sul do México e da América Central, mas adaptou-se em quase todo o Brasil, sendo cultivado desde o Sul do Estado de São Paulo até a Região Amazônica. Apesar dessa planta adaptar-se às mais diferentes condições de solo, clima e altitude, seu desenvolvimento e produção são favorecidos por altas temperaturas e umidade (Gomes, 1987).

No Nordeste Brasileiro, as condições climáticas adequadas para produção do sapotizeiro, associadas ao uso da fertirrigação, têm favorecido a produção de frutos durante todo o ano e propiciado uma renda constante para os produtores (Bandeira et al., 2003).

A Embrapa Agroindústria Tropical recentemente lançou as cultivares BRS-227 (Sapoti Ipacuru) e BRS-228 (Sapota Tropical). O fruto de formato ovóide é conhecido, no Nordeste brasileiro, como "sapoti”, e o de formato arredondado como "sapota", por ser semelhante ao fruto de espécie da mesma família, Pouteria sapota.

O sapoti é um fruto climatérico; portanto, o início do processo de amadurecimento depende do pico climatérico. Tem-se observado que os valores dos picos de atividade respiratória e produção de etileno e o tem- 
po que decorre entre a colheita e o início do climatérico variam muito entre cultivares de sapoti (Selvaraj \& Pal, 1984; Latifah, 1996; Miranda, 2002).

A perecibilidade de um fruto climatérico pode ser avaliada em função do pico respiratório climatérico e sua produção de etileno. Melhor entendimento do metabolismo de amadurecimento do sapoti subsidiaria propostas de tecnologias para melhor conservação deste fruto.

O objetivo deste trabalho foi avaliar alterações físicas, fisiológicas e químicas, durante a maturação de duas cultivares de sapoti, relacionando-as às taxas respiratórias e de liberação de etileno.

\section{Material e Métodos}

Os frutos utilizados foram provenientes de um pomar experimental do vale do Curu, da Embrapa Agroindústria Tropical, no Município de Paraibapa, CE. Esse pomar de sapotizeiro foi instalado em 1995, com mudas provenientes de materiais multiplicados vegetativamente na Empresa Pernambucana de Pesquisa Agropecuária (IPA). As produções das plantas, mantidas sob fertirrigação, foram acompanhadas por um período de oito anos, e com o resultado, selecionaram-se duas cultivares, BRS-227 (Sapoti Ipacuru) e BRS-228 (Sapota Tropical).

Os frutos foram colhidos no estádio de maturação fisiológica, selecionados e separados em dois grupos: um grupo (controle), avaliado no dia da colheita, e o outro, armazenado em temperatura de $26 \pm 2^{\circ} \mathrm{C}$ e umidade relativa (UR) de $55 \pm 5 \%$. A atividade respiratória e a produção de etileno foram determinadas diariamente, e as demais variáveis (perda de massa, firmeza, acidez titulável, $\mathrm{pH}$, sólidos solúveis, açúcares solúveis e senescência) foram avaliadas aos 0 , 2, 4, 6, 8, 10 e 12 dias de armazenamento.

A atividade respiratória e a produção de etileno foram determinadas utilizando-se cromatógrafo de gás, com detectores de condutividade térmica para $\mathrm{CO}_{2}$ e de ionização de chamas para etileno. Na avaliação da perda de massa, utilizou-se balança semi-analítica e os resultados, expressos em porcentagem, foram obtidos a partir da diferença entre o peso inicial e o peso no dia da avaliação. A firmeza da polpa foi determinada por meio de texturômetro computadorizado da marca Stable Micro Systems, modelo TA.XT2i, por meio de leitura em cada lado do fruto, e os resultados foram expressos em newton $(\mathrm{N})$.

O teor de sólidos solúveis totais (SST) foi medido utilizando-se um refratômetro digital com correção auto- mática de temperatura, conforme método da Association of Official Analytical Chemists (1992). A acidez total titulável (ATT) foi determinada utilizando-se o método do Instituto Adolfo Lutz (1985). A avaliação do pH foi realizada por meio de potenciômetro. O conteúdo de açúcares solúveis totais (AST) foi analisado segundo Yemn \& Willis (1954). Na avaliação da senescência, adotou-se escala subjetiva, com notas de $1-5$, de acordo com a porcentagem de frutos afetados por incidência de manchas, infecção por fungos e enrugamento (1: ausência de danos; 2: 1-25\%; 3: 26-50\%; 4: 51-75\%; e 5: 76-100\%) (Miranda et al., 2000).

O delineamento experimental foi o inteiramente casualizado, em esquema fatorial $2 \times 7$, constituído de duas cultivares (BRS-227 e BRS-228) e sete tempos de armazenamento (0, 2, 4, 6, 8, 10 e 12 dias), com três repetições de três frutos. Os dados foram submetidos à análise de variância. Para a comparação entre cultivares, utilizouse o teste $\mathrm{F}$ a $5 \%$ de probabilidade e para os períodos de armazenamento, utilizaram-se modelos de ajustamentos da regressão simples (Pimentel-Gomes, 1987).

\section{Resultados e Discussão}

As cultivares BRS-228 e BRS-227 apresentaram picos respiratórios de $64,14 \mathrm{mg} \mathrm{kg}^{-1} \mathrm{~h}^{-1}$ aos dez dias, e $62,49 \mathrm{mg} \mathrm{kg}^{-1} \mathrm{~h}^{-1}$ aos oito dias, depois da colheita, respectivamente (Figura 1). O pico de produção de etileno ocorreu no mesmo dia do pico respiratório (oitavo dia), para a cultivar BRS-227, e atingiu 2,09 $\mathrm{mL} \mathrm{kg}^{-1} \mathrm{~h}^{-1}$. Na cultivar BRS-228, o pico de etileno aconteceu um dia antes do pico respiratório e atingiu $3,10 \mathrm{~mL} \mathrm{~kg}^{-1} \mathrm{~h}^{-1}$.

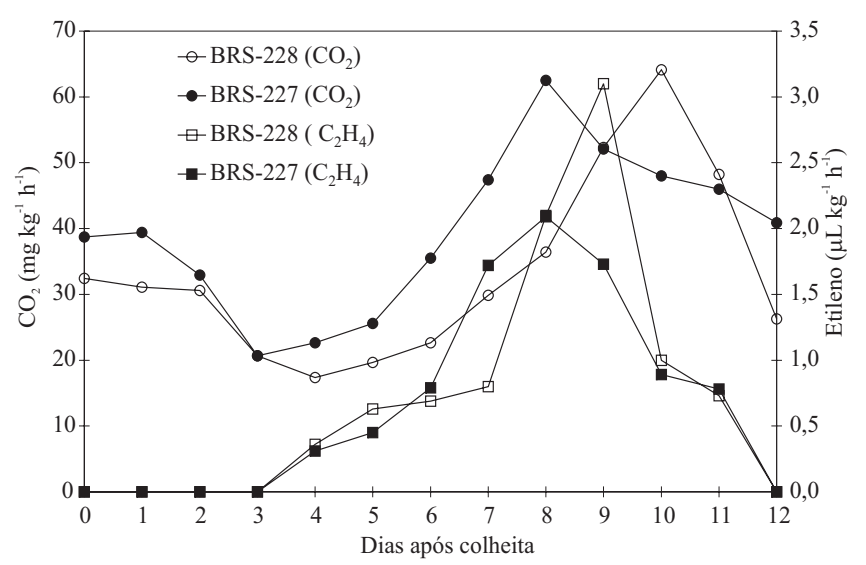

Figura 1. Atividade respiratória $\left(\mathrm{CO}_{2}\right)$ e produção de etileno $\left(\mathrm{C}_{2} \mathrm{H}_{4}\right)$ de duas cultivares de sapoti, cujos frutos foram armazenados à temperatura de $26 \pm 2^{\circ} \mathrm{C}$ e umidade relativa de $55 \pm 5 \%$. 
Selvaraj \& Pal (1984) também verificaram uma pequena diferença no pico respiratório entre as cultivares Cricker Ball e Oblong, que apresentaram pico de $100 \mathrm{e}$ $93 \mathrm{mg} \mathrm{kg}^{-1} \mathrm{~h}^{-1}$ de $\mathrm{CO}_{2}$ aos 4,5 e 3,5 dias depois da colheita, respectivamente. Miranda (2002) observou, em frutos de sapoti armazenados em condição ambiente $\left(28^{\circ} \mathrm{C}\right.$ e $60 \%$ UR), pico respiratório em torno de $47 \mathrm{mg} \mathrm{kg}^{-1} \mathrm{~h}^{-1}$ no oitavo dia da colheita, e pico de etileno de $1,8 \mathrm{~mL} \mathrm{~kg}^{-1} \mathrm{~h}^{-1}$, um dia antes do pico respiratório.

Houve interação significativa entre cultivar e tempo de armazenamento, para perda de massa. A cultivar BRS-227 apresentou maior susceptibilidade para perda de massa do que a BRS-228, tendo alcançado 22,3\% de perda de massa aos 12 dias de armazenamento (Figura 2). As duas cultivares apresentaram sinais de enrugamento - perda de turgidez celular provocada por desidratação. A desidratação pós-colheita dos frutos tem grande importância comercial, já que estes são comercializados por peso. Apesar de a perda de água não afetar, significativamente, as reações bioquímicas que ocorrem durante o amadurecimento (Chitarra \& Chitarra, 1990), provoca enrugamento que compromete a aparência do fruto, e ocasiona perda do valor comercial. Miranda (2002) também observou perda de $23 \%$ de massa ao final de 30 dias de armazenamento, quando transferiu os frutos da refrigeração para temperatura ambiente. Araújo-Neto (2001) verificou 15,6\% de perda de massa, no 8 - dia de armazenamento à temperatura de $24 \pm 1^{\circ} \mathrm{C}$ e $55 \pm 5 \%$ UR. Miranda et al. (2000) verificaram que o uso de atmosfera modificada reduz a perda de massa de sapoti armazenado à temperatura ambiente, por manter uma atmosfera com alta umidade dentro da embalagem.

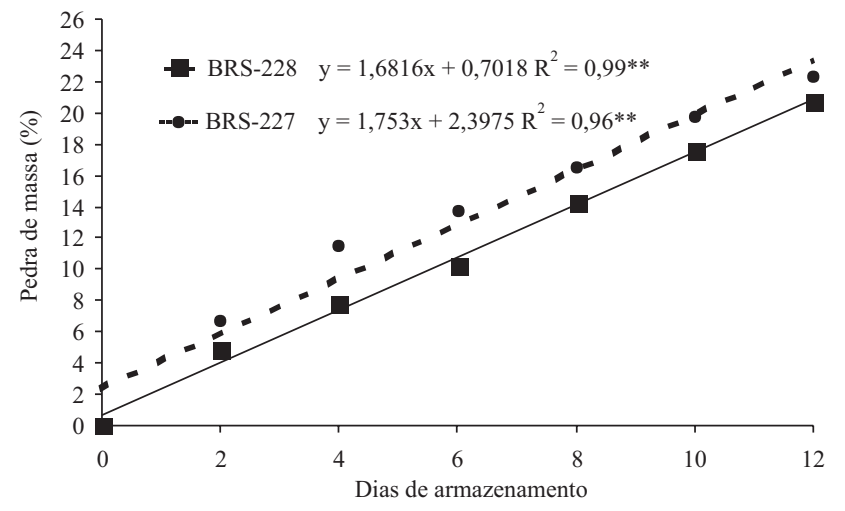

Quanto à firmeza, houve interação significativa entre cultivar e tempo de armazenamento. A queda na firmeza dos frutos da cultivar BRS-227 foi de 84,91 para 5,19 N, no final do armazenamento, enquanto para BRS-228 foi de 80,88 para 30,31 N (Figura 2). Esses resultados indicam que o amolecimento da cultivar BRS-227 foi bem mais acelerado do que da BRS-228. Observando-se os valores de firmeza, verifica-se que o amolecimento foi maior depois do climatérico, na cultivar BRS-227. Acentuada redução da firmeza, durante o armazenamento, tem sido observada em outros trabalhos com sapoti (Abdul-Karim et al., 1987; Araújo-Neto et al., 2001). A redução da firmeza durante o amadurecimento, provavelmente, é resultante do mecanismo de hidrólise da parede celular e da lamela média, pois as enzimas responsáveis pela hidrólise da parede celular geralmente são dependentes de etileno, justificando a acentuada perda de firmeza depois do climatérico (Redgwell \& Fischer, 2002).

A interação entre os fatores estudados não foi significativa para a acidez titulável (ATT), mas os fatores isolados foram significativos. Houve redução na acidez a partir do quarto dia de armazenamento, porém no final do armazenamento ocorreu aumento (Figura 3), provavelmente em virtude da ocorrência de fermentação, com o início da senescência (Miranda, 2002). Essa redução da acidez, durante o armazenamento do fruto, é ocasionada por sua utilização na respiração ou conversão em açúcares (Wills et al., 1998). O valor médio de ATT para a cultivar BRS-228 $(0,23 \%)$ foi maior do que para a cultivar BRS-227 (0,21\%). Para variável $\mathrm{pH}$, apenas o fator tempo foi significativo, tendo sido observada pequena queda no $\mathrm{pH}$ ao longo do armazenamento (Figura 3). A variação de ATT não está

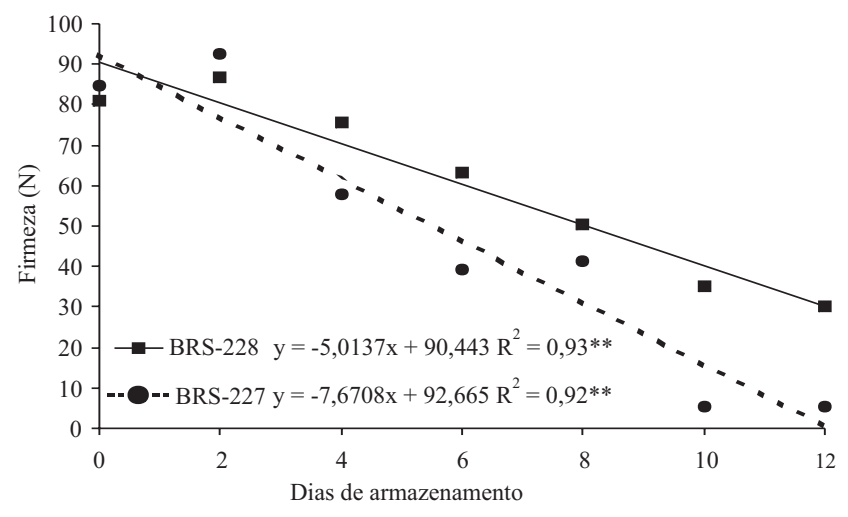

Figura 2. Perda de massa e firmeza de duas cultivares de sapoti, cujos frutos foram armazenados à temperatura de $26 \pm 2^{\circ} \mathrm{C}$ e umidade relativa de $55 \pm 5 \%$. 
diretamente relacionada ao $\mathrm{pH}$, pois o $\mathrm{pH}$ depende tanto da concentração de íons $\mathrm{H}^{+}$livres, quanto da capacidade tamponante do suco ou polpa. Velez-Colón et al. (1989), verificaram variação muito pequena nos valores de ATT e $\mathrm{pH}$, entre as 14 cultivares de sapoti. Costa et al. (2000) observaram, no dia da colheita, para a cultivar Itapirema, valores de $\mathrm{pH}$ semelhantes aos deste trabalho, porém o decréscimo durante o armazenamento foi mais acentuado, provavelmente em virtude da temperatura mais elevada.

Houve interação significativa entre os fatores cultivar e tempo de armazenamento, para as variáveis SST e AST. Durante o armazenamento foi pequena a variação nos teores de SST e AST, tendo-se observado, no geral, um pequeno aumento seguido de um decréscimo depois do climatérico (Figura 4). Esses resultados concordam com as observações de Ramadan et al. (1983) de que não existe acumulação de açúcares em sapoti depois da colheita. Também se observa que a cultivar BRS-228 apresentou maior conteúdo de SST e AST, no dia da colheita e durante

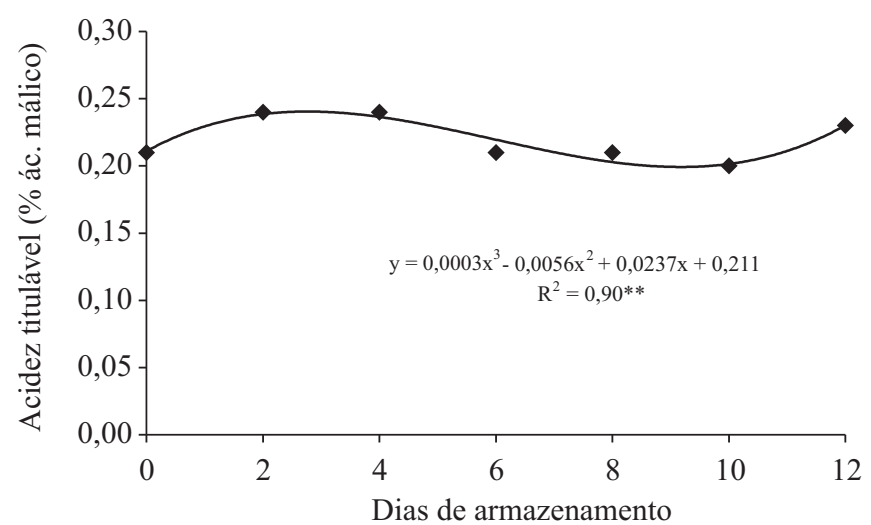

todo período de armazenamento (Figura 4). Em frutos com alto teor de açúcares, como o sapoti, ocorre uma alta correlação entre o aumento no conteúdo de açúcares solúveis e de sólidos solúveis (Alves et al., 2000). Lakshminarayana \& Moreno-Rivera (1979) relatam que existem diferenças nos teores de açúcares entre as cultivares Indiana e Mexicana, tendo a última apresentado um conteúdo de açúcar maior e mais consistente. Segundo Huertas et al. (1999), essa redução no teor de SST, no final do armazenamento, indica que estes sólidos estão sendo mais usados na respiração do que produzidos, ou seja, é o início da senescência. Acredita-se que o aumento no conteúdo de sacarose do sapoti, durante a maturação, seja proveniente não somente da degradação do amido e hemicelulose, mas também da degradação do látex do fruto, causada por microrganismos ou enzimas do próprio látex (Pathak \& Bhat, 1952).

A cultivar BRS-228 senesceu mais lentamente do que a BRS-227 (Figura 5). Logo depois do pico climatérico,

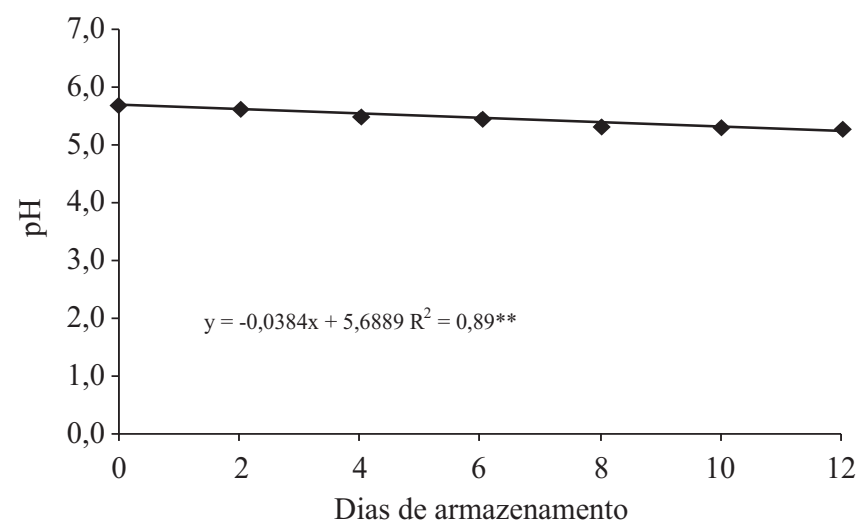

Figura 3. Acidez titulável e $\mathrm{pH}$ de duas cultivares de sapoti, cujos frutos foram armazenados à temperatura de $26 \pm 2^{\circ} \mathrm{C}$ e umidade relativa de $55 \pm 5 \%$.
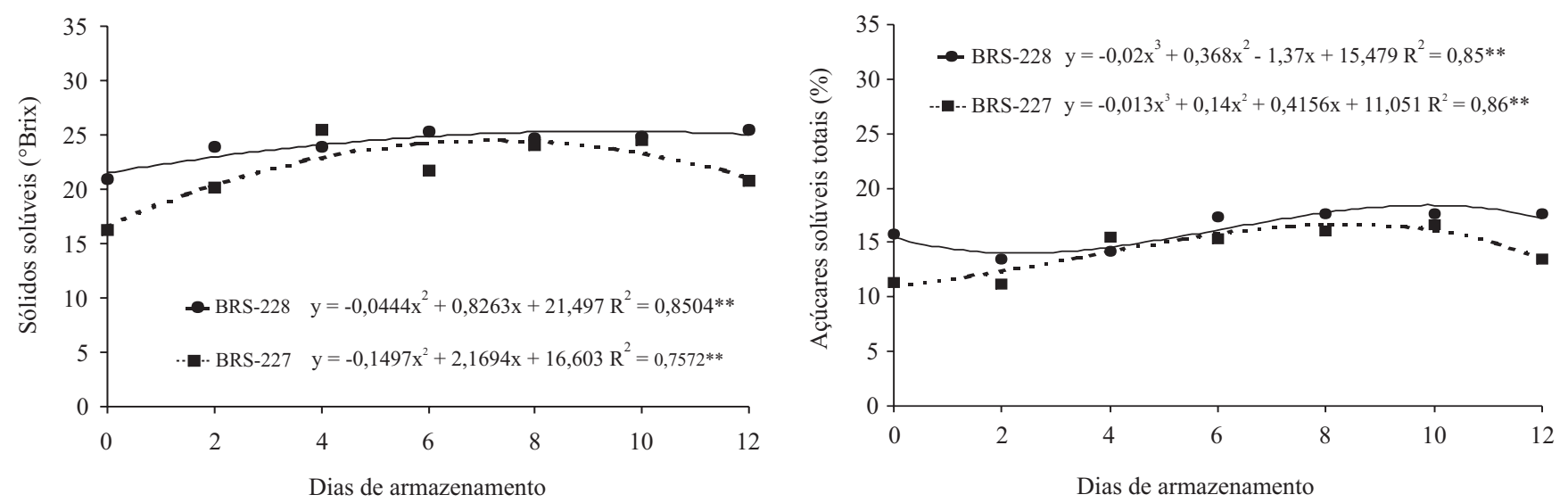

Figura 4. Sólidos solúveis e açúcares solúveis totais de duas cultivares de sapoti, cujos frutos foram armazenados à temperatura de $26 \pm 2^{\circ} \mathrm{C}$ e umidade relativa de $55 \pm 5 \%$. 


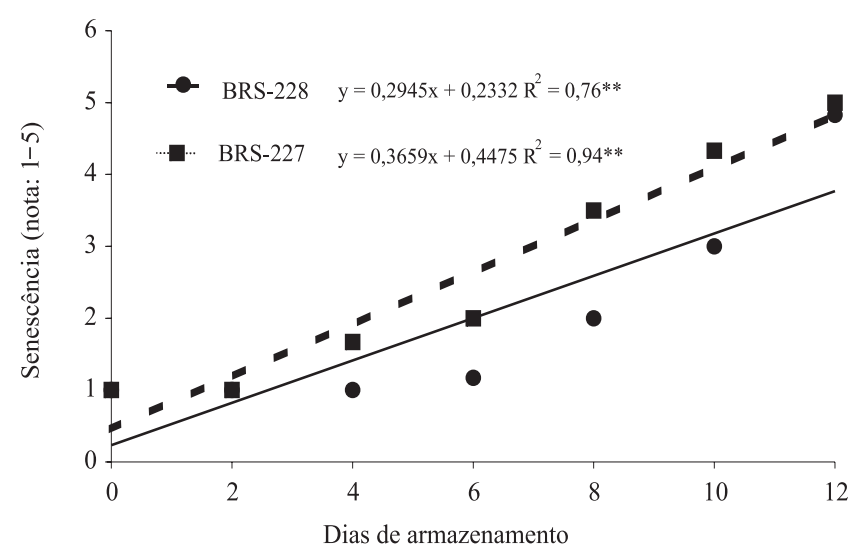

Figura 5. Senescência de duas cultivares de sapoti, cujos frutos foram armazenados à temperatura de $26 \pm 2^{\circ} \mathrm{C}$ e umidade relativa de $55 \pm 5 \%$. Notas de $1-5 ; 1$ : ausência de danos; 2: 1-25; 3: 26-50; 4: 51-75; 5: 76-100\% de frutos afetados.

as duas cultivares iniciaram a senescência, apresentando aroma característico de fermentação alcoólica. Comportamento semelhante foi observado por Miranda et al. (2000), em duas espécies de sapoti estudadas.

\section{Conclusões}

1. A cultivar BRS-228 apresenta pico respiratório, produção de etileno e senescência retardados, em relação à cultivar BRS-227.

2. A cultivar BRS-228 apresenta maior firmeza, maiores teores de sólidos solúveis e açúcares solúveis totais, e menor perda de massa do que a cultivar BRS-227.

3. A cultivar BRS-228 apresenta maior potencial de conservação pós-colheita do que a cultivar BRS-227.

\section{Referências}

ABDUL-KARIM, M.N.B.; TARMIZI, S.A.; BAKAR, A.A. The physico-chemical changes in ciku (Achras sapota L.) of Jantung variety. Pertanika, v.10, p.277-282, 1987.

ALVES, R.E.; FILGUEIRAS, H.A.C.; MOURA, C.F.H. Sapoti. In: ALVES, R.E.; FILGUEIRAS, H.A.C.; MOURA, C.F.H. (Ed.). Caracterização de frutas nativas da América Latina. Jaboticabal: Funep, 2000. p.55-58. (Frutas nativas, 9).

ARAÚJO-NETO, S.E.; PRAÇA, E.F.; CARVALHO, E.F.; ALVES, R.E.; MENEZES, J.B.; MORAIS, E.A. Determinação do ponto de colheita e índices de maturação para sapoti (Manilkara achras (Mill.) Fosberg). Revista Brasileira de Fruticultura, v.23, p.45-49, 2001.

ASSOCIATION OF OFFICIAL ANALYTICAL CHEMISTS. Official methods of analysis of the Association of Official Analytical Chemistry. $11^{\text {th }}$ ed. Washington, 1992. 1115p.
BANDEIRA, C.T.; MESQUITA, A.L.M.; AQUINO, A.R.L. de; CAVALCANTI JUNIOR, A.T.; SANTOS, F.J. de S.; OLIVEIRA, F.N.S.; SOUZA NETO, A.J. de; BARROS, L. de M.; BRAGA SOBRINHO, R.; LIMA, R.N. de; OLIVEIRA, V.H. de. O cultivo do sapotizeiro. Fortaleza: Embrapa Agroindústria Tropical, 2003. 20p. (Embrapa Agroindústria Tropical. Circular técnica, 13).

CHITARRA, M.I.F.; CHITARRA, A.B. Pós-colheita de frutos e hortaliças: fisiologia e manuseio. Lavras: Esal/Faepe, 1990. 293p.

COSTA, M.L. da; MENEZES, J.B.; PRAÇA, E.F.; OLIVEIRA, O.F. de. Algumas características do fruto do sapotizeiro Itapirema31 durante o desenvolvimento e o armazenamento. Caatinga, v.13, p.15-18, 2000.

GOMES, R.P. Fruticultura brasileira. 11.ed. São Paulo: Nobel, 1987. 446p.

HUERTAS, G.G.C.; MORENO, N.G.N.; SAURI, D.E. Conservación refrigerada de chicozapote com calentamiento intermitente. Horticultura Mexicana, v.7, p.258, 1999.

INSTITUTO ADOLFO LUTZ. Normas analíticas do Instituto Adolfo Lutz: métodos químicos e físicos para análise de alimentos. 3.ed. São Paulo, 1985. v.1, 533p.

LAKSHMINARAYANA, S.; MORENO-RIVERA, M.A. Proximate characteristics and composition of sapodilla fruits grown in Mexico. Proceedings of the Florida State Horticultural Society, v.92, p.303-305, 1979.

LATIFAH, M.N. Effect of exogenous ethylene in the ripening of ciku (Achras sapota). In: INTERNATIONAL CONFERENCE ON TROPICAL FRUITS, 3., 1996, Kuala Lampur, Malaysia. Proceedings. [Kuala Lumpur]: Malaysian Agricultural Research and Development Institute, 1996. v.1, p.367-376.

MIRANDA, M.R.A. de. Alterações fisiológicas e histológicas durante o desenvolvimento, maturação e armazenamento refrigerado do sapoti. 2002. 136p. Tese (Doutorado) - Universidade Federal do Ceará, Fortaleza.

MIRANDA, M.R.A. de; SILVA, F.S. da; ALVES, R.E.; FILGUEIRAS, H.A.C.; ARAÚJO, N.C.C. Armazenamento de dois tipos de sapoti sob condição de ambiente. Revista Brasileira de Fruticultura, v.24, p.644-646, 2000.

PATHAK, S.; BHAT, J.V. Studies on the carbohydrate metabolism of Achras zapota L. fruit. Journal of the University of Bombay, v.21, p.11-20, 1952.

PIMENTEL-GOMES, F. Curso de estatística experimental. São Paulo: Nobel, 1987. 467p.

RAMADAN, L.; MENDOZA, M.; OSUNA, M.; PANZZA, C. Acumulación de azúcares, pérdida de textura y contenido de solidos solubles totales en nispero (Achras sapota) variedad Conchudo. Revista de la Faculdad de Agronomía de la Universidad del Zulia, v.6, p.744-757, 1983.

REDGWELL, R.J.; FISCHER, M. Fruit texture, cell wall metabolism and consumer perceptions. In: KNEE, M. (Ed.). Fruit quality and its biological basis. Sheffield, UK: Sheffield Academic Press, 2002. p.46-75. 
SELVARAJ, Y.; PAL, D.K. Changes in the chemical composition and enzyme activity of two sapodilla (Manilkara zapota) cultivars during development and ripening. Journal of Horticultural Science, v.59, p.275-281, 1984.

VELEZ-COLÓN, R.; CALONI, I.B. de; MARTINEZGARRASTAZU, S. Sapodilla (Manilkara sapota Linn.) variety trials at Southern Puerto Rico. Journal of Agriculture of the University of Puerto Rico, v.73, p.255-264, 1989.
WILLS, R.; McGLASSON, W.B.; GRAHAM, D.; JOYCE, D. Postharvest: an introduction to the physiology and handling of fruit, vegetables and ornamentals. $4^{\text {th }}$ ed. New York: CABI International, 1998. 276p.

YEMM, E.W.; WILLIS, A.J. The estimation of carbohydrates in plant extracts by anthrone. Biochemical Journal, v.57, p.508-514, 1954.

Recebido em 21 de janeiro de 2005 e aprovado em 24 de agosto de 2005 